\title{
Musculoskeletal ultrasonographic evaluation of perineural injection therapy versus therapeutic ultrasound in chronic lateral epicondylitis
}

Mohja Ahmed El-Badawy ${ }^{1 *}$, Hanaa Ahmed El-Nagaar ${ }^{2}$, Mona Mansour Mohammed ${ }^{1}$, Naglaa Youssef Assaf ${ }^{1}$ and Reem Mohammed Ezz El-Din EL-Mallah

\begin{abstract}
Background: Lateral epicondylitis (LE) is a common disorder causing pain and functional limitations especially in athletes and manual workers. There is a growing interest in regenerative injection therapies in chronic LE. One of those suggested is perineural injection (PNI) therapy. The present study aims to find out the efficacy of PNI therapy in the treatment of chronic LE as compared to therapeutic ultrasound (TUS) and to detect if any changes have happened after treatment to the common extensor tendon (CEO) as detected by diagnostic ultrasound (US) examination.
\end{abstract}

Results: Statistical analysis between the 2 groups at the start of the study as regards age, sex, and clinical parameters including visual analog scale (VAS), tenderness grading scale, and Patient-Rated Tennis Elbow Evaluation (PRTEE) Questionnaire revealed a non-significant difference between both groups ( $p>0.05)$. After 12 weeks, withingroup analysis showed significant improvement in all clinical outcome measures in both groups compared to the initial assessment.

Between-group analysis after 12 weeks showed that the tenderness grading scale and PRTEE score had more significant improvement in the PNI therapy group. However, the two groups were comparable regarding VAS. Within-group US evaluation at the 12th week post-treatment showed a highly significant decrease in hypoechoic areas $(p<0.001)$ and a decrease in distributed fibrillar pattern in PNI group, while the TUS group demonstrated a significant decrease in hypoechoic areas and tendon thickness $(p<0.005)$. Between-group US evaluation after 12 weeks showed no significant difference in all assessed US parameters. No complications were observed in both groups.

Conclusions: A short-term follow-up regimen of 1 session/week of PNI therapy is significantly more effective than 3 sessions/week of TUS regarding the improvement of pain and functional status. Yet both therapeutic modalities were able to produce significantly positive structural changes in the CEO. The current study highlights the neurogenic inflammation as the primary pain generator in chronic LE and the advantage of its treatment with PNI therapy in chronic and refractory cases.

Keywords: Perineural injection therapy, Lateral epicondylitis, Therapeutic ultrasound, Musculoskeletal US, Neurogenic inflammation

\footnotetext{
* Correspondence: mohjaelbadawy@gmail.com

${ }^{1}$ Rheumatology and Rehabilitation, Faculty of Medicine, Ain Shams

University, 2069 Zahraa Madinat Nasr, Cairo, Egypt

Full list of author information is available at the end of the article
}

\section{Springer Open}

( ) The Author(s). 2021 Open Access This article is licensed under a Creative Commons Attribution 4.0 International License, which permits use, sharing, adaptation, distribution and reproduction in any medium or format, as long as you give appropriate credit to the original author(s) and the source, provide a link to the Creative Commons licence, and indicate if changes were made. The images or other third party material in this article are included in the article's Creative Commons licence, unless indicated otherwise in a credit line to the material. If material is not included in the article's Creative Commons licence and your intended use is not permitted by statutory regulation or exceeds the permitted use, you will need to obtain permission directly from the copyright holder. To view a copy of this licence, visit http://creativecommons.org/licenses/by/4.0/. 


\section{Background}

Lateral elbow pain is a very common disorder affecting both athletes and office workers, with a strong relation to trauma and hard labor activities [1]. Lateral epicondylitis (LE) pathology was described as a chronic degeneration of the wrist extensor tendons including their attachment at the lateral epicondyle of the humerus [2]. Despite its relatively high prevalence, there is no consistent algorithm of management. It was found that most cases are self-limiting and well-managed with simple pain medication [2]. However, dominant arm affection, manual work, and longer duration of symptoms are usually associated with a poor prognosis [3].

Conservative therapies in acute and sub-acute cases of LE include rest, non-steroidal anti-inflammatory drugs (NSAIDs), physical therapy (removed), shockwave therapy, braces, therapeutic ultrasound (TUS), low-level laser therapy (LLLT), and steroid injection [4]. Recent biologic therapies, including autologous whole-blood injections (ABIs), platelet-rich plasma (PRP), and stem cell therapy, are also considered for the non-surgical management of LE [4].

A growing interest has been developed in the perineural injection (PNI) therapy or neural prolotherapy [5]. A neuropathic inflammation was suggested by Reeves and Lyftogt $[5,6]$, which is produced by special small sensory nerves that are protein-producing "peptidergic". These nerves normally produce proteins that can be healing or damaging. Dextrose injection in low concentration (5\%) was claimed to reduce neuropathic inflammation.

In PNI therapy, 5\% dextrose is injected around the superficial sensory nerves. This leads to pain relief, regression of soft tissue edema, and relief of chronic constriction insertion $(\mathrm{CCI})$, restoring the flow of normal nerve growth factor flow, stimulating nerve repair, and providing immediate analgesic effect lasting from hours to days [6].

It was found that TUS provides modest pain reduction in LE over 1 to 3 months [7]. Most of the studies evaluating the modalities used in the treatment of LE were assessed by subjective pain scores and none of them used besides objective assessment tools. The present study aimed to investigate the short-term clinical and radiologic effectiveness of PNI therapy versus TUS in patients with chronic LE in producing structural changes in the common extensor tendon (CEO) corresponding to the clinically subjective improvement of pain score.

\section{Methods}

The Ethical Committee of our university approved the present study, and all patients signed informed consent before participation.

This was a prospective randomized controlled clinical study conducted at the outpatient's clinic of the Physical
Medicine, Rheumatology, and Rehabilitation Department from December 2018 to March 2020. Randomization was allocated by the numbered envelope method. Participants were included if they had a clinical diagnosis of LE, defined as pain on the lateral side of the elbow for at least 6 months duration as well as the failure of at least one of the conservative treatments of LE such as the intake of NSAIDs and PT. The diagnosis of LE was proved if there was local tenderness just anterior and distal to the lateral epicondyle and positivity of any of the following provocative tests $[8,9]$ :

1. Cozen's test. The examiner stabilizes the patient's forearm and asks the patient to make a fist, pronate the forearm, and extend the wrist towards radial deviation, whereas the physician resists this motion. Pain at the lateral epicondyle indicates a positive test.

2. Mill's test. The examiner palpates the lateral epicondyle with one hand, using the other hand to pronate the patient's forearm, fully flex the wrist, and extend the elbow joint.

3. Maudsley's test. The examiner makes a resisted extension of the patient's middle finger with the elbow in full extension and the forearm in pronation $[8,9]$.

All patients in both groups were evaluated using clinical assessment scales as well as musculoskeletal US evaluation before and 12-weeks post-intervention.

Exclusion criteria included corticosteroid injection within the past 3 months and other medical or physical treatments within the last month, previous elbow surgery or trauma, systemic inflammatory diseases, pregnancy or breast-feeding, infection at the injection site, clinical evidence of other primary sources of lateral elbow pain, malignancy, diabetes, thyroid dysfunction, hemophilia, neurological deficits in the ipsilateral upper limb, and cognitive dysfunction.

The sample size was initially calculated on the collected 46 cases, with a confidence level of $90 \%$ and a $10 \%$ margin of error; the ideal sample was 28 cases (http://www.quattrics.com).

According to the treatment modality, the allocated patients were randomly divided into two equal groups. They were instructed to avoid the use of non-trial treatment modalities. Participants were instructed to avoid anti-inflammatory medications during treatment and to stop these medications $48-72 \mathrm{~h}$ before starting (remove this sentence) while treated by either therapy modalities. Non-prescription analgesics as Panadol were permitted as required.

A matched block method was performed to generate the random sequence of envelope allocations. Each block 
allocation was assigned using simple randomization. Then, this block sequence is repeated via swapping the order of the two treatment groups, giving an equal number of patients in both groups over the matched block. The block size was selected randomly to be 5,10 , or 15 to prevent sequence anticipation. A random number generator within the statistical analysis package SPSS was used to provide the random sequence for these blocks.

Thereafter, allocations were printed onto cards and then sealed in sequentially numbered envelopes and provided to participating clinicians. Once a patient has consented to enter the study, an envelope is opened and the patient is then offered the allocated treatment regimen.

\section{PNI therapy group}

In this group, we used $500 \mathrm{ml}$ of $5 \%$ dextrose buffered with $2.4 \mathrm{ml}$ sodium bicarbonate $8.4 \%$ for injection. At each session, the elbow was palpated for tender points along the course of cutaneous branches of radial and musculocutaneous nerves around the lateral epicondyle followed by good sterilization with alcohol. Each tender point was injected at subcutaneous tissue level with 0.5$1 \mathrm{ml}$ of buffered glucose $5 \%$ per injection point with insulin syringe in the tender points around the lateral epicondyle, at weekly intervals between injections for 8 settings [10]. No side effects were reported in our patients apart from pain at the injection site that is relieved within a few hours post-injection without taking any analgesic.

\section{TUS group}

The ultrasound device used was ENRAF NONUS, with $1 \mathrm{~cm}^{2}$ transducer, at $1.5 \mathrm{~W} / \mathrm{cm}^{2}$ and $3 \mathrm{MHz}$ frequency, with a continuous mode on the painful area for $5 \mathrm{~min}$ once/day, 3 days/week, for 12 sessions in total [11].

\section{Outcome assessment}

The primary outcomes assessed in this study were the Patient-Rated Tennis Elbow Evaluation (PRTEE) score $[12,13]$ and musculoskeletal US evaluation. PRTEE score is a validated patient outcome measure specifically designed for LE. It is used to assess pain severity and functional disability. It is a 15-item questionnaire including a 5-item pain subscale and a 10-item function subscale for assessment of affected limb during the previous week.

Patients were asked to rank the degree of their pain during activities using a scale from 0 to 10 , with a 10 score representing the worst pain. Also, higher scores on the function scale correspond to more difficulty accomplishing activities of daily living $[12,13]$.

Secondary outcomes included the tenderness grading scale [14] and the visual analog scale (VAS) for assessment of pain [15]. Tenderness grading scale grading is as follows: $0=$ no tenderness, $\mathrm{I}=$ tenderness to palpation without grimace or flinch, II = tenderness with grimace and/or flinch to palpation, III = tenderness with withdrawal (+ "Jump Sign"), and IV = withdrawal $(+$ "Jump Sign") to non-noxious stimuli (i.e., superficial palpation, pinprick, gentle percussion) [14]. In the VAS, the patient is asked to rate the intensity of lateral elbow pain using a $10-\mathrm{cm}$ line where zero points to no pain and 10 points to the worst pain [15].

The musculoskeletal US was done using a high-quality ultrasound scanner (General Electric); model LOGIC P5 with a multi-frequency linear probe $(5-12 \mathrm{MHz})$ was used to scan the common extensor tendon origin (CETO) by both greyscale and power Doppler US. Transverse and longitudinal scans were done according to the European League Against Rheumatism (EULAR) guidelines. The grayscale US with standardized B-mode image settings (frequency, depth, and gain were adjusted). The primary findings in case of tendinopathy included tendon enlargement, hypoechoic areas that represent collections of micro-tears, calcification, irregular bone growth, cortical bony lesions as bone irregularities, bone erosions, osteophytes, and enthesophytes. These findings give the tendinous insertion a diffused heterogeneous appearance that points towards the diagnosis of LE [16]. The thickness of the common extensor tendon (CET) was measured on the longitudinal image putting in consideration to show best anatomical details of the tendon using a 5-mm distance from the radiohumeral joint margin as the standard reference point, where the tendon thickness was measured on a longitudinal scan in which a perpendicular line is traced between the tendon surface and the cortical bony interface of lateral epicondyle [16, 17].

Moreover, standardized power Doppler US settings (Doppler frequency $5 \mathrm{MHz}$, the pulse repetition frequency of $800 \mathrm{~Hz}$, wall filter $85 \mathrm{~Hz}$, gain $22.5 \%$ ) was done for detection of neovascularity within the same region. We used absent or present $(0 / 1)$ score for each US finding including the U/S assessment of CET for presence or absence of hypoechoic areas, heterogenecity (disturbed fibrillar pattern), tendon thickness, presence of osteophytes, enthesophytes, calcifications, bone irregularities, and power Doppler signals [18].

All patients in both groups were evaluated using clinical assessment scales as well as musculoskeletal US evaluation before and 12-weeks post-intervention.

\section{Statistical analysis}

Data were collected and analyzed by Statistical Package for Social Science (IBM SPSS) version 20. The qualitative data were analyzed using the Chi-square test and/or Fisher exact test. An independent $t$ test was used for 
quantitative data. The $p$ value was considered nonsignificant if $p>0.05$, significant if $p \leq 0.05$, highly significant (HS) if $p \leq 0.01$, and very highly significant if $p$ $\leq 0.001$.

\section{Results}

This study was conducted on 30 patients divided equally into two groups. The flow chart of patients is demonstrated in Fig. 1. We found no significant difference in demographic and clinical data between both patients' groups (Table 1). The pre-treatment clinical and ultrasonographic findings were statistically comparable in both groups (Table 2).

Post-intervention in the PNI therapy group, all clinical scores were very highly significantly lower than corresponding values before treatment ( $p$ value $\leq 0.001$ ). Meanwhile, ultrasonographic re-evaluation showed a very highly significant decrease in presence of CET

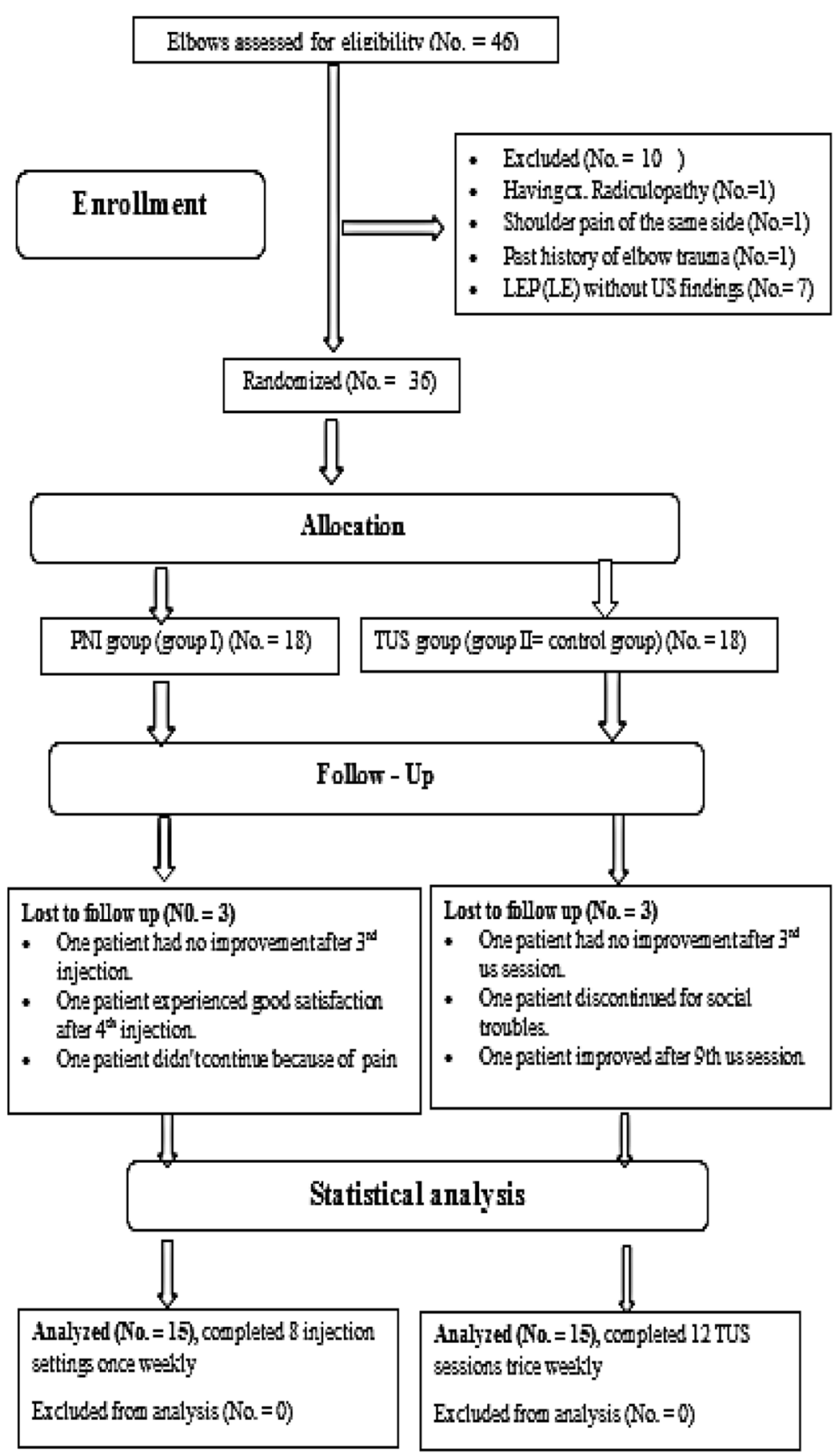

Fig. 1 The flow chart of patients 
Table 1 Comparison of demographic and clinical data between both patients' groups

\begin{tabular}{|c|c|c|c|c|c|c|}
\hline \multirow[t]{2}{*}{ Demographic and clinical data } & \multicolumn{2}{|c|}{ Group I, PNI therapy $(N=15)$} & \multicolumn{2}{|c|}{ Group II, TUS therapy $(N=15)$} & \multirow[t]{2}{*}{$p$ value } & \multirow[t]{2}{*}{ Significance } \\
\hline & Mean & SD & Mean & SD & & \\
\hline Age & 44.40 & 10.45 & 47.80 & 10.76 & 0.39 & $N S^{*}$ \\
\hline Disease duration (months) & 11.80 & 7.62 & 17.60 & 15.65 & 0.21 & $N S^{*}$ \\
\hline \multirow[t]{2}{*}{ Median } & 12 & & 11 & & & \\
\hline & $N$ & $\%$ & $N$ & $\%$ & & \\
\hline \multicolumn{7}{|l|}{ Sex } \\
\hline Male & 1 & 6.67 & 2 & 13.33 & 0.543 & $N S^{\pi}$ \\
\hline Female & 14 & 93.33 & 13 & 86.67 & & \\
\hline \multicolumn{7}{|l|}{ Occupation } \\
\hline Manual & 13 & 86.67 & 12 & 80 & 1 & NS" \\
\hline Non-manual & 2 & 13.33 & 3 & 20 & & \\
\hline \multicolumn{7}{|l|}{ Dominant hand } \\
\hline Right & 14 & 93.33 & 14 & 93.33 & 1 & NS \\
\hline Left & 1 & 6.67 & 1 & 6.67 & & \\
\hline \multicolumn{7}{|l|}{ Affected elbow } \\
\hline Right & 9 & 0.60 & 8 & 0.53 & 0.713 & NS ${ }^{\circ}$ \\
\hline Left & 6 & 0.40 & 7 & 0.47 & & \\
\hline \multicolumn{7}{|l|}{ Cozen's test } \\
\hline Positive & 13 & 86.67 & 12 & 80 & 1 & NS \\
\hline Negative & 2 & 13.33 & 3 & 20 & & \\
\hline \multicolumn{7}{|l|}{ Mill's test } \\
\hline Positive & 10 & 66.67 & 11 & 73.33 & 1 & NS \\
\hline Negative & 5 & 33.33 & 4 & 26.67 & & \\
\hline \multicolumn{7}{|l|}{ Modsley's test } \\
\hline Positive & 9 & 0.60 & 8 & 0.53 & 0.713 & NS \\
\hline Negative & 6 & 0.40 & 7 & 0.47 & & \\
\hline
\end{tabular}

Statistical methods used "Student $t$ test, " $C$ hi-square test, and "Fisher exact test

The $p$ value was considered non-significant (NS) if $p>0.05$, significant (S) if $p \leq 0.05$, highly significant (HS) if $p \leq 0.01$, and very highly significant (HS) if $p \leq 0.001$.

The table showed no significant difference in demographic and clinical data between both patients' groups $(p>0.05)$

hypoechoic areas $(p$ value $\leq 0.001)$ and a significant decrease in the disturbed fibrillar pattern $(p$ value $=0.025)$ (Table 3, Figs. 2 and 3).

In the TUS therapy group, all clinical scores were very highly significantly lower than the corresponding values before treatment ( $p$ value $<0.001$ ). As regards ultrasonographic findings post-intervention, the presence of CET hypoechoic areas were significantly decreased ( $p$ value $=$ 0.02 ) and the tendon thickness was significantly diminished as compared to pre-treatment values ( $p$ value $=$ 0.026) (Table 4, Figs. 4 and 5).

On comparing post-intervention outcome measures in both groups, it was found that the tenderness grading scale and PRTEE score were more significantly decreased in PNI therapy group than in the TUS therapy group ( $p$ values 0.043 and 0.025 ), respectively. Meanwhile, VAS was statistically comparable in both groups.
Similarly, US findings were statistically comparable in both groups post-treatment (Table 5).

\section{Discussion}

In the current study, both methods seem to be an independently valid option for the treatment of lateral epicondylitis; the more significant clinical effect was found for the PNI therapy in improving the tenderness grading scale and PRTEE score when compared to the TUS in the short-term follow-up, while the decrease in pain score and radiological improvements were comparable in both groups post-intervention.

Our results in the PNI therapy group are comparable to those of Lyftogt's study, where he used subcutaneous prolotherapy for treatment of refractory lateral elbow pain and found a significant reduction in VAS with $100 \%$ patient satisfaction rate [10]. 
Table 2 Comparison of tenderness grading scale, pain intensity measured by VAS scale, PRTEE score, and US findings before treatment in both groups

\begin{tabular}{|c|c|c|c|c|}
\hline Clinical scores & $\begin{array}{l}\text { PNI therapy group (pre-treatment) } \\
(n=15)\end{array}$ & $\begin{array}{l}\text { TUS therapy group (pre-treatment) } \\
(n=15)\end{array}$ & $\begin{array}{l}p \\
\text { value }\end{array}$ & Significance \\
\hline $\begin{array}{l}\text { Tenderness grading scale [median } \\
\text { (range)] }\end{array}$ & $2(1-3)$ & $2(2-3)$ & 0.15 & $N S^{*}$ \\
\hline VAS [median (range)] & $8(4-10)$ & $8(5-10)$ & 0.71 & $N S^{*}$ \\
\hline PRTEE score (mean \pm SD) & $53.29 \pm 15.69$ & $48.13 \pm 9.58$ & 0.29 & $\mathrm{NS}^{*}$ \\
\hline US findings & $\begin{array}{l}\text { US findings pre-treatment (PNI } \\
\text { group) }\end{array}$ & $\begin{array}{l}\text { US findings pre-treatment (TUS } \\
\text { group) }\end{array}$ & $\begin{array}{l}p \\
\text { value }\end{array}$ & Significance \\
\hline Hypoechoic area in CET (+ve/-ve) no. & $14 / 1$ & $13 / 2$ & 1 & $N S^{\S}$ \\
\hline $\begin{array}{l}\text { Disturbed fibrillar pattern (+ve/-ve) } \\
\text { no. }\end{array}$ & $9 / 6$ & $11 / 4$ & 0.439 & $N S^{q}$ \\
\hline Tendon thickness $(\mathrm{cm})($ mean $\pm \mathrm{SD})$ & $0.534 \pm 0.043$ & $0.549 \pm 0.072$ & 0.482 & $N S^{\S}$ \\
\hline Enthesophyte (+ve/-ve) no. & $9 / 6$ & $8 / 7$ & 0.713 & $N S^{\natural}$ \\
\hline Osteophyte (+ve/-ve) no. & $4 / 11$ & $3 / 12$ & 1 & $N S^{\S}$ \\
\hline Calcification (+ve/-ve) no. & $4 / 11$ & $3 / 12$ & 1 & $N S^{\S}$ \\
\hline $\begin{array}{l}\text { Bone surface irregularity/erosion (+ve/ } \\
\text {-ve) no. }\end{array}$ & $8 / 7$ & $10 / 5$ & 0.456 & NS" \\
\hline Tendon tear (+ve/-ve) no. & $1 / 14$ & $1 / 14$ & 1 & $N S^{\S}$ \\
\hline Power Doppler signal (+ve/-ve) no. & $4 / 11$ & $4 / 11$ & 1 & $N S^{\natural}$ \\
\hline
\end{tabular}

Statistical methods used "Chi-square test, *Student $t$ test, and ${ }^{5}$ Fisher exact test

CET common extensor tendon

The $p$ value was considered non-significant (NS) if $p>0.05$, significant (S) if $p \leq 0.05$, highly significant (HS) if $p \leq 0.01$, and very highly significant (HS) if $p<0.001$ The table showed a non-significant difference in the pre-treatment clinical and ultrasonographic findings in both patient groups $(p>0.05$ )

Table 3 Comparison of tenderness grading scale, pain intensity measured by VAS scale, PRTEE score, and US findings before and after treatment in PNI therapy group

\begin{tabular}{|c|c|c|c|c|}
\hline Clinical scores & $\begin{array}{l}\text { PNI therapy group } \\
\text { (pre-treatment) }(n=15)\end{array}$ & $\begin{array}{l}\text { PNI therapy group (post- } \\
\text { treatment) }(n=15)\end{array}$ & $p$ value & Significance \\
\hline Tenderness grading scale [median (range)] & $2(1-3)$ & $1(0-2)$ & $<0.001$ & Very $\mathrm{HS}^{\sigma}$ \\
\hline VAS [median (range)] & $8(4-10)$ & $2(1-5)$ & $<0.001$ & Very HS $^{\sigma}$ \\
\hline PRTEE score (mean \pm SD) & $53.29 \pm 15.69$ & $24.4 \pm 11.86$ & $<0.001$ & Very $\mathbf{H S}^{\sigma}$ \\
\hline US findings & $\begin{array}{l}\text { US findings pre- } \\
\text { treatment (PNI group) }\end{array}$ & $\begin{array}{l}\text { US findings post- } \\
\text { treatment (PNI group) }\end{array}$ & $p$ value & Significance \\
\hline Hypoechoic area in CET (+ve/-ve) no. & $14 / 1$ & $3 / 12$ & $<0.001$ & Very $\mathrm{HS}^{\S}$ \\
\hline Disturbed fibrillar pattern (+ve/-ve) no. & $9 / 6$ & $3 / 12$ & 0.025 & $s^{\sharp}$ \\
\hline Tendon thickness $(\mathrm{cm})($ mean $\pm \mathrm{SD})$ & $0.53 \pm 0.04$ & $0.53 \pm 0.04$ & 0.131 & $\mathrm{NS}^{*}$ \\
\hline Enthesophyte (+ve/-ve) no. & $9 / 6$ & $8 / 7$ & 0.713 & $N S^{\natural}$ \\
\hline Osteophyte (+ve/-ve) no. & $4 / 11$ & $4 / 11$ & 1 & $N S^{\S}$ \\
\hline Calcification (+ve/-ve) no. & $4 / 11$ & $3 / 12$ & 1 & $N S^{\S}$ \\
\hline Bone surface irregularity/erosion (+ve/-ve) no. & $8 / 7$ & $8 / 7$ & 1 & NS $S^{\natural}$ \\
\hline Tendon tear (+ve/-ve) no. & $1 / 14$ & $1 / 14$ & 1 & $N S^{\S}$ \\
\hline Power Doppler signal (+ve/-ve) no. & $4 / 11$ & $0 / 15$ & 0.1 & NS" \\
\hline
\end{tabular}

Statistical methods used ${ }^{\sigma}$ paired Student $t$ test, ${ }^{1}$ Chi-square test, ${ }^{*}$ Student $t$ test, and ${ }^{5}$ Fisher exact test

CET common extensor tendon

The $p$ value was considered non-significant (NS) if $p>0.05$, significant (S) if $p \leq 0.05$, highly significant (HS) if $p \leq 0.01$, and very highly significant (HS) if $p<0.001$ All clinical scores were very highly significantly lower than corresponding values before treatment ( $p$ value $<0.001$ ). Ultrasonographic evaluation post-PNI treatment showed a very highly significant decrease in the presence of CET hypoechoic areas $(p$ value $<0.001)$ and a significant decrease in the disturbed fibrillar pattern $(p$ value $=0.025)$ 


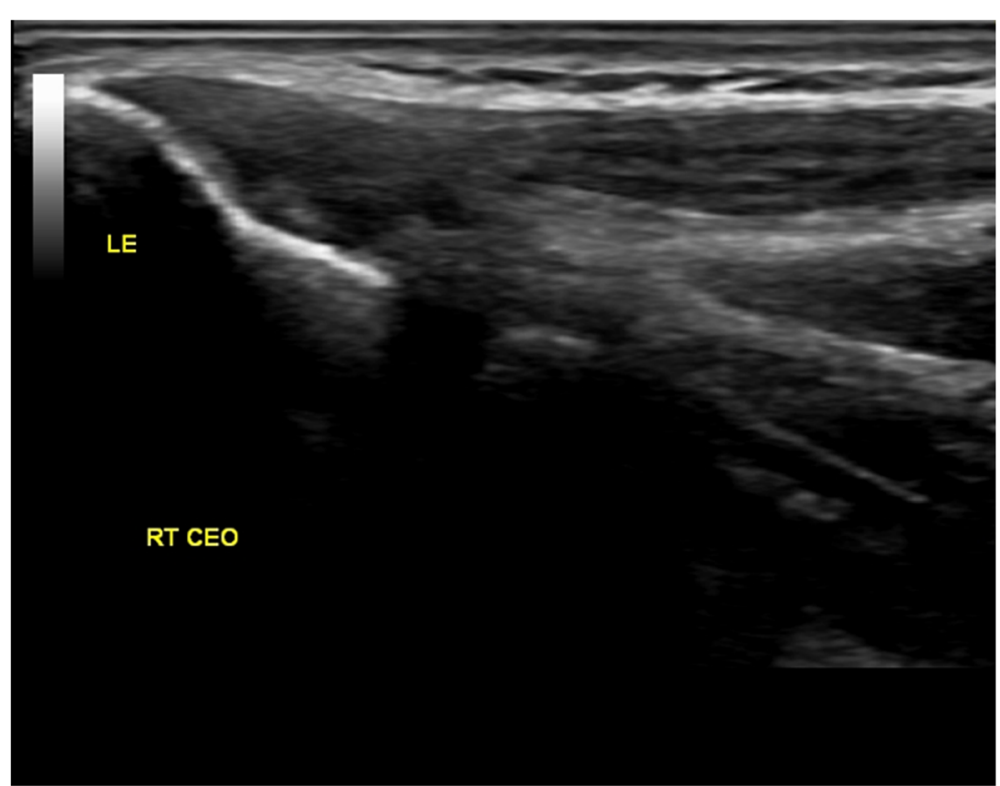

Fig. 2 US picture showing hypoechoic area and disturbed fibrillar pattern of Rt. CEO tendon in a patient before PNI treatment. LE, lateral epicondyle; RT, right common extensor origin

Besides, the results of the PNI group matched with those of 3 previous studies using dextrose deep prolotherapy in the treatment of LE as regards improvement of pain [19-21].

Also, evidence of tendon healing was observed via US imaging as diffuse fibrillar patterns in previously anechoic lesions and areas of hyper-vascularity [21].

PNI therapy therapeutic effect is based on the concept of Bystander disease that explains how superficial nerve pathology can affect deeper anatomic structures [22, 23].
Bystander disease is based on "Hilton's law" that states that the nerve supplying a joint also supplies both the muscles that move the joint and the skin covering the articular attachment of those muscles. The musculocutaneous nerve supplies pain and proprioception to the elbow and at the same time, it is the nerve supply to the biceps brachii and brachialis muscles, as well as the skin close to the attachments of these muscles [22, 23].

Hilton's law explains how the healing of a superficial nerve pathology through PNI can improve the

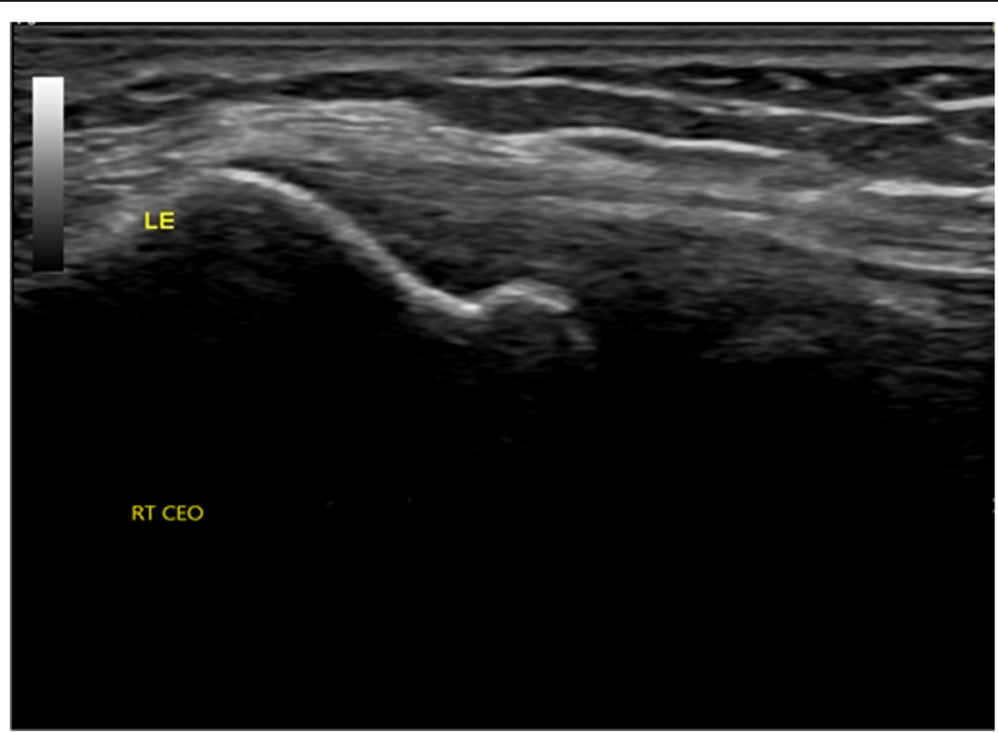

Fig. 3 US picture showing improvement of hypoechogenicity and fibrillar pattern of Rt. CEO tendon in the same patient after PNI treatment. LE, lateral epicondyle; RT, right common extensor origin 
Table 4 Comparison of tenderness grading scale, pain intensity measured by VAS scale, PRTEE score, and US findings before and after treatment in TUS therapy group

\begin{tabular}{|c|c|c|c|c|}
\hline Clinical scores & $\begin{array}{l}\text { TUS therapy group (pre- } \\
\text { treatment) }(n=15)\end{array}$ & $\begin{array}{l}\text { TUS therapy group (post- } \\
\text { treatment) }(n=15)\end{array}$ & $p$ value & Significance \\
\hline Tenderness grading scale [median (range)] & $2(2-3)$ & $2(1-3)$ & $<0.001$ & Very $\mathrm{HS}^{\sigma}$ \\
\hline VAS [median (range)] & $8(5-10)$ & $2(1-7)$ & $<0.001$ & Very $\mathbf{H S}^{\sigma}$ \\
\hline PRTEE score (mean \pm SD) & $48.13 \pm 9.58$ & $33.27 \pm 8.40$ & $<0.001$ & Very $\mathbf{H S}^{\sigma}$ \\
\hline US findings & $\begin{array}{l}\text { US findings pre-treatment } \\
\text { (TUS group) }\end{array}$ & $\begin{array}{l}\text { US findings post-treatment } \\
\text { (TUS group) }\end{array}$ & $p$ value & Significance \\
\hline Hypoechoic area in CET (+ve/-ve) no. & $3 / 12$ & $7 / 8$ & 0.020 & $\mathbf{S}^{\S}$ \\
\hline Disturbed fibrillar pattern (+ve/-ve) no. & $11 / 4$ & $7 / 8$ & 0.136 & $N S^{\S}$ \\
\hline Tendon thickness $(\mathrm{cm})($ mean $\pm \mathrm{SD})$ & $0.55 \pm 0.07$ & $0.53 \pm 0.07$ & 0.026 & $\mathrm{~S}^{*}$ \\
\hline Enthesophyte (+ve/-ve) no. & $8 / 7$ & $7 / 8$ & 0.715 & $N S^{\S}$ \\
\hline Osteophyte (+ve/-ve) no. & $3 / 12$ & $3 / 12$ & 1 & $N S^{\S}$ \\
\hline Calcification (+ve/-ve) no. & $3 / 12$ & $2 / 13$ & 1 & $N S^{\S}$ \\
\hline Bone surface irregularity/erosion (+ve/-ve) no. & $10 / 5$ & $9 / 6$ & 0.705 & $N S^{\pi}$ \\
\hline Tendon tear (+ve/-ve) no. & $1 / 14$ & $1 / 14$ & 1 & $N S^{\S}$ \\
\hline Power Doppler signal (+ve/-ve) no. & $4 / 11$ & $1 / 14$ & 0.330 & NS" \\
\hline
\end{tabular}

Statistical methods used ${ }^{\sigma}$ paired Student $t$ test, ${ }^{1} \mathrm{Chi}$-square test, ${ }^{*}$ Student $t$ test, and ${ }^{5}$ Fisher exact test

CET common extensor tendon

The $p$ value was considered non-significant (NS) if $p>0.05$, significant (S) if $p \leq 0.05$, highly significant (HS) if $p \leq 0.01$, and very highly significant (HS) if $p<0.001$ All clinical scores were very highly significantly lower than the corresponding values before treatment $(p$ value $<0.001)$. Ultrasonographic findings post-

intervention showed a significantly decrease of CET hypoechoic areas $(p$ value $=0.02)$ the tendon thickness as compared to pre-treatment values $(p$ value $=0.026)$

endogenous structure of CEOT as we found in US evaluation post-intervention [23]..

The transition from acute to chronic pain in LE is characterized by the release of pain-producing neuropeptides including substance $\mathrm{P}$ and calcitonin generelated peptide (CGRP). Activated $\mathrm{C}$ fibers producing these neuropeptides in a process termed neurogenic inflammation which is characterized by an absence of leukocytes [24].

Neurogenic inflammation was first termed "inflammatory neuritis" by Dr. George Hackett [25, 26]. Peptidergic sensory nerves are important for maintaining the health

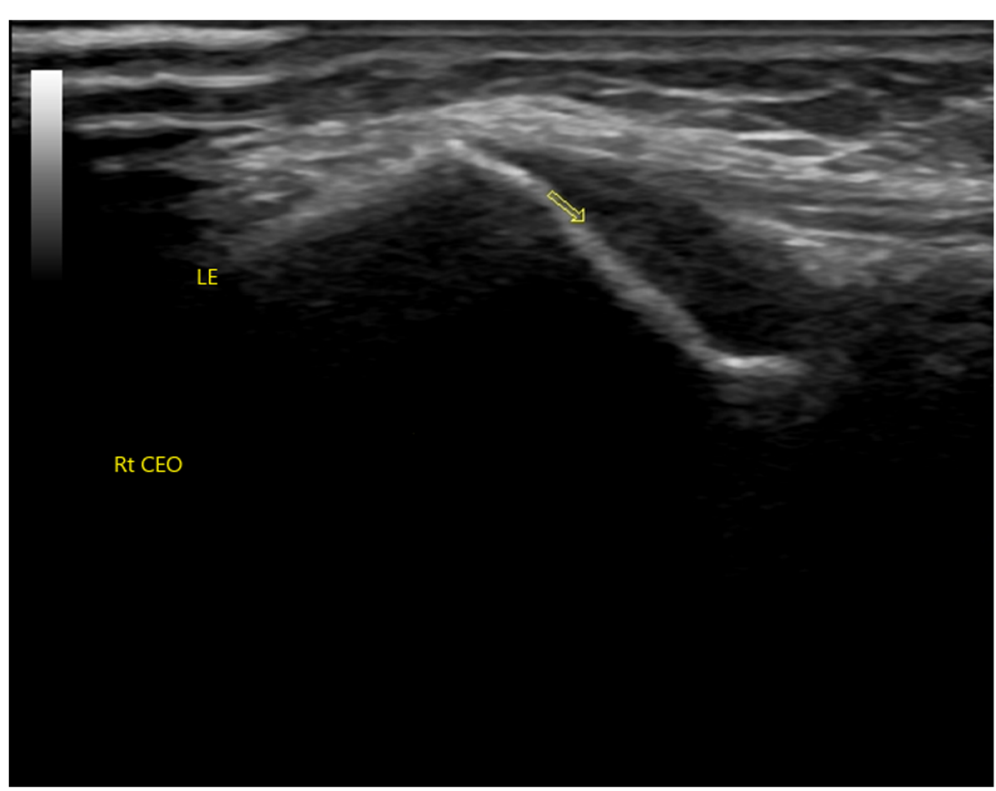

Fig. 4 US picture showing disturbed fibrillar pattern of Rt. CEO tendon of a patient before US treatment. LE, lateral epicondyle; RT, right common extensor origin 


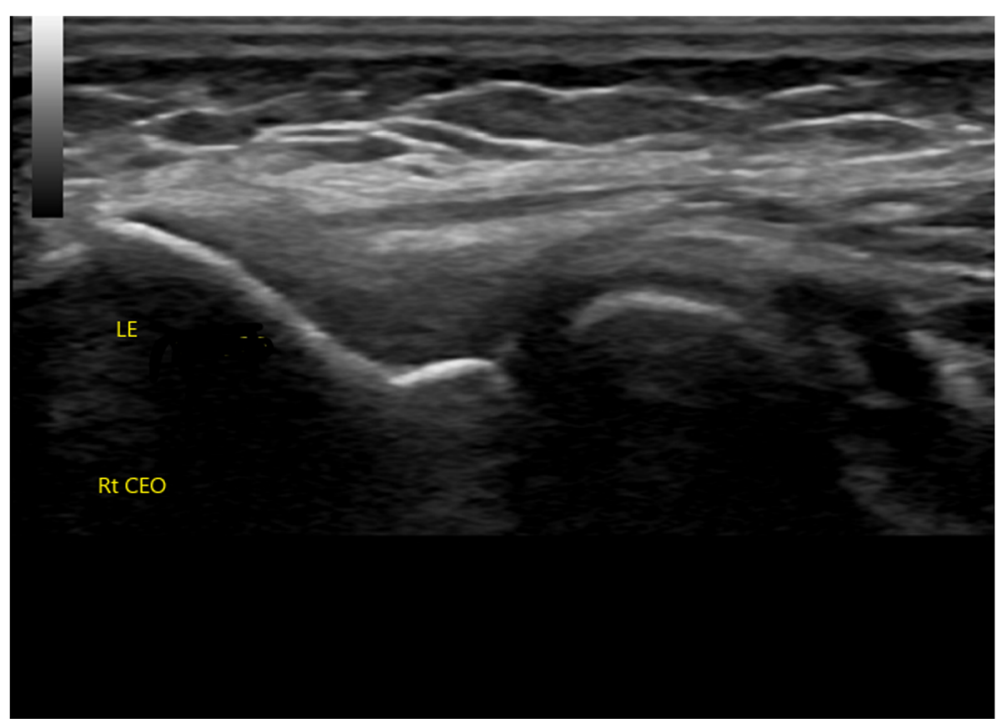

Fig. 5 US picture showing nearly normal fibrillar pattern of CEO of the same patient after US treatment. LE, lateral epicondyle; RT, right common extensor origin

and renewal of joint structures, as tendons and ligaments. These nerves are sensitized due to trauma, injury, or constriction and represent sites of neurogenic inflammation $[27,28]$.

It was found that dextrose $5 \%$ injections at the sites of sensitized nerves can completely eliminate pain from neurogenic inflammation through inhibition of transient receptor potential vanilloid 1
(TRPV1) receptors through the stoppage of substance $P$ and CGRP, which are known to induce pain and swelling of the nerve and/or surrounding tissues [29]. Given that sensorimotor changes have been consistently demonstrated in LE [30], PNI of the radial nerve and its branches could be a reasonable alternative option for patients with refractory LE.

Table 5 Comparison of tenderness grading scale, pain intensity measured by VAS scale, PRTEE score, and US findings after treatment in both groups

\begin{tabular}{|c|c|c|c|c|}
\hline Clinical scores & $\begin{array}{l}\text { PNI therapy group } \\
\text { (post-treatment) }(n=15)\end{array}$ & $\begin{array}{l}\text { TUS therapy group } \\
\text { (post-treatment) }(n=15)\end{array}$ & $p$ value & Significance \\
\hline Tenderness grading scale [median (range)] & $1(0-2)$ & $2(1-3)$ & 0.043 & $\mathrm{~S}^{*}$ \\
\hline VAS [median (range)] & $2(1-5)$ & $2(1-7)$ & 0.234 & $\mathrm{NS}^{*}$ \\
\hline PRTEE score (mean \pm SD) & $24.40 \pm 11.86$ & $33.27 \pm 8.40$ & 0.025 & $\mathbf{s}^{*}$ \\
\hline US findings & $\begin{array}{l}\text { US findings post-treatment } \\
\text { (PNI group) }\end{array}$ & $\begin{array}{l}\text { US findings post-treatment } \\
\text { (TUS group) }\end{array}$ & $p$ value & \\
\hline Hypoechoic area in CET (+ve/-ve) no. & $3 / 12$ & $7 / 8$ & 0.121 & $N S^{\S}$ \\
\hline Disturbed fibrillar pattern (+ve/-ve) no. & $3 / 12$ & $7 / 8$ & 0.121 & $N S^{n}$ \\
\hline Tendon thickness $(\mathrm{cm})($ mean \pm SD) & $0.529 \pm 0.044$ & $0.529 \pm 0.067$ & 1 & $\mathrm{NS}^{*}$ \\
\hline Enthesophyte (+ve/-ve) no. & $8 / 7$ & $7 / 8$ & 0.715 & $N S^{\natural}$ \\
\hline Osteophyte (+ve/-ve) no. & $4 / 11$ & $3 / 12$ & 1 & $N S^{\S}$ \\
\hline Calcification (+ve/-ve) no. & $3 / 12$ & $2 / 13$ & 1 & $N S^{\S}$ \\
\hline Bone surface irregularity/erosion (+ve/-ve) no. & $8 / 7$ & $9 / 6$ & 0.713 & $N S^{\natural}$ \\
\hline Tendon tear (+ve/-ve) no. & $1 / 14$ & $1 / 14$ & 1 & $N S^{\S}$ \\
\hline Power Doppler signal (+ve/-ve) no. & $0 / 15$ & $1 / 14$ & 1 & NS $S^{\pi}$ \\
\hline
\end{tabular}

Statistical methods used "Chi-square test, ${ }^{*}$ independent $t$ test, and ${ }^{5}$ Fisher exact test

CET common extensor tendon

The $p$ value was considered non-significant (NS) if $p>0.05$, significant (S) if $p \leq 0.05$, highly significant (HS) if $p \leq 0.01$, and very highly significant (HS) if $p<0.001$ The table showed that the tenderness grading scale and the PRTEE score were more significantly decreased in PNI therapy group than in the TUS therapy group post-intervention ( $p$ values 0.043 and 0.025 ), respectively. The VAS and US findings manifest a statistically non-significant differences in both groups post-treatment 
In the TUS group, the results are in agreement with those of Murtezani et al. [31], who observed that therapeutic exercise combined with TUS was effective in the intermediate- and long-term treatment of patients with LE. Also, our study results go with those of LangenPieters et al. [32], who reported significant effects of pain reduction and functional improvement in favor of continuous ultrasound therapy versus chiropractic therapy.

TUS produces thermal and mechanical effects on the target tissue leading to increased metabolism, circulation, extensibility of connective tissue, and tissue regeneration. It was suggested that TUS provides modest pain reduction over 1 to 3 months in LE [7].

On US assessment, lateral epicondylitis appears as tendon enlargement and heterogeneity. Tears may be seen as hypoechoic areas with adjacent discontinuity and may be partial or full-thickness tears [33]. Neovascularization occurring in a tear could be visualized with power Doppler US [34].

Post-intervention U/S assessment was comparable in both groups, where the PNI group showed a highly significant decrease in the presence of CET hypoechoic areas and a significant decrease in a disturbed fibrillar pattern when compared to the pre-treatment US assessment. While the US group showed a significant decrease in CET hypoechoic areas and tendon thickness.

The ultrasonic assessment was previously done by Kang before and 1 month after the treatment of 12 patients with LE with five sessions of $15 \%$ dextrose prolotherapy. After dextrose prolotherapy, all of the ultrasounds showed improvements in a pattern in the form of filling in of the anechoic foci with fibrillar pattern and smaller anechoic foci indicating the repair of the torn or degenerated extensor tendons [35]. This technique used dextrose injection but the injection was directed to the tendon itself (deep prolotherapy) which may be somehow painful to the patient and it did not target the neural innervation of the LE like the perineural injection and its regenerative effect is directed to the tendon itself, while our study used only $5 \%$ glucose which was directed to the branches of the radial nerves.

To the best of our knowledge, no similar studies have used the same clinical outcome measures and ultrasonographic evaluation in the assessment and follow-up of PNI of LE. Also, no recent studies addressing the use of PNI therapy in the treatment of chronic LE are done. However, a recent study of Apaydin et al. found that both hyaluronic acid and dextrose prolotherapy injections were effective in reducing pain and improving grip strength and function in patients with chronic LE. They reported that dextrose prolotherapy injection was more effective in terms of pain relief and functional outcome in the short term as compared to hyaluronic acid injection [36].
Also, the study of Waglee et al. addresses the use of ultrasound-guided perineural anesthetic injections around the posterior antebrachial cutaneous nerve in chronic and refractory LE. An average pain relief duration was 26.5 days in the patient group that received local anesthetic injection combined with corticosteroid compared to an average duration of $15 \mathrm{~h}$ post-injection in the group that received an only local anesthetic injection. Both previous studies are using different modalities of treatment in chronic LE than our study [37].

The small sample size is considered the main limitation of the present study. So there was a chance of a type 1 error when comparing outcomes. Additional larger studies are needed to further examine the efficacy of PNI therapy in chronic LE. Another limitation is that we did not measure the difference as regards age, gender, occupation, dominant, and affected arm side in response to the used procedures. We consider this a limitation of our study and recommend further studies to address the effect of these factors on the patients' response to treatment.

The perineural injection could have resulted in regeneration of the nerve supply to the affected LE which caused relief of pain and increase in function and regeneration of the diseased enthesis helping the regenerating fibers to realign in its proper direction as pain decreases and function improves with therapy. It may also have caused hydro-dissection of the small sensory fibers which would probably result in a decrease in the nerve edema and swelling and stimulated their regenerative power which would have led to amelioration of the neurogenic inflammation.

\section{Conclusions}

PNI therapy is a safe, low-cost, and effective method that improves pain and functional status in patients with chronic LE. PNI therapy is significantly more effective than TUS regarding tenderness and functional status improvement. Yet both therapeutic modalities were effective in improving the pain and producing positive structural changes in the CEO. The current study highlights neurogenic inflammation as an important possible generator of pain in chronic LE.

\footnotetext{
Abbreviations

LE: Lateral epicondylitis; PNI: Perineural injection; TUS: Therapeutic ultrasound; CEO: Common extensor tendon; VAS: Visual analog scale; PRTEE: Patient-Rated Tennis Elbow Evaluation; NSAIDs: Non-steroidal antiinflammatory drugs; PT: Physical therapy; LLLT: Low-level laser therapy; ABIs: Autologous whole-blood injections; PRP: Platelet-rich plasma; CCl: Chronic constriction insertion; EULAR: European League Against Rheumatism; CET: Common extensor tendon; SPSS: Statistical Package for Social Science; HS: Highly significant; CGRP: Calcitonin gene-related peptide; TRPV1: Transient receptor potential vanilloid 1
}

Acknowledgements Not applicable. 


\section{Authors' contributions}

MA wrote the paper with revision. HA followed the patients and collected the patients' data. MM gave the idea, put study design, and revised the manuscript. NYA revised the statistics. RM performed the therapeutic ultrasound before and after intervention and revised the methodology. They all approved the final version of the manuscript.

\section{Funding}

This study had no funding from any resource.

\section{Availability of data and materials}

The datasets used and/or analyzed during the current study are available from the corresponding author on reasonable request.

\section{Ethics approval and consent to participate}

This study was approved by the Research Ethics Committee (REC) of the Faculty of Medicine at Ain Shams University in Egypt. REC code is FWA 000017585 . All patients included in this study gave written informed consent to participate in this research. Reference number of approval, FMASU R 51 / 2020.

\section{Consent for publication}

All patients included in this research gave written informed consent to publish the data contained within this study.

\section{Competing interests}

The authors declare that they have no competing interests.

\section{Author details}

'Rheumatology and Rehabilitation, Faculty of Medicine, Ain Shams University, 2069 Zahraa Madinat Nasr, Cairo, Egypt. ${ }^{2}$ Rheumatology and Rehabilitation, El-Matarya Teaching Hospital, Cairo, Egypt.

\section{Received: 24 September 2020 Accepted: 23 November 2020} Published online: 06 January 2021

\section{References}

1. Obuchowicz R, Bonczar M (2016) Ultrasonographic differentiation of lateral elbow pain. Ultrasound Int Open 2(02):E38-E46

2. Ahmad Z, Siddiqui N, Malik SS, Abdus-Samee M, Tytherleigh-Strong G, Rushton N (2013) Lateral epicondylitis: a review of pathology and management. Bone Joint J 95(9):1158-1164

3. Newcomer KL, Martinez-Silvestrini JA, Schaefer MP, Gay RE, Arendt KW (2005) Sensitivity of the patient-rated forearm evaluation questionnaire in lateral epicondylitis. J Hand Ther 18(4):400-406

4. Lai WC, Erickson BJ, Mlynarek RA, Wang D (2018) Chronic lateral epicondylitis: challenges and solutions. Open Access J Sports Med 9:p243

5. Reeves KD (2007) Prolotherapy: regenerative injection therapy. In: Pain management. WB Saunders, Philadelphia, pp 1106-1127

6. Lyftogt J (2010) Neural Prolotherapy Workshop meeting. The Hackett Hemwall Foundation and the Italian Society for Prolotherapy, Ferrara

7. Smidt N, Assendelft W, Arola H, Malmivaara A, Green S, Buchbinder R et al (2003) Effectiveness of physiotherapy for lateral epicondylitis: a systematic review. Ann Med:51-62

8. VCIII D, Grimmer KA, Milanese S, Kumar S (2014) The sensitivity of the provocation tests in replicating pain on the lateral elbow area of participants with lateral epicondylalgia. J Case Rep Clin Res Stud 1(1):1

9. Radpasand M, Owens E (2009) Combined multimodal therapies for chronic tennis elbow: pilot study to test protocols for a randomized clinical trial. J Manip Physiol Ther 32(7):571-585

10. Lyftogt J (2007) Subcutaneous prolotherapy treatment of refractory knee, shoulder, and lateral elbow pain. Austr Musculoskel Med 12(2):110

11. Yalvaç B, Mesci N, Külcü D G, \&Yurdakul OV (2018). Comparison of ultrasound and extracorporeal shock wave therapy in lateral epicondylosis, Acta Orthop Traumatol Turc, 52(5); 357 - 362.

12. MacDermid JC (2007) The Patient-Rated Tennis Elbow Evaluation (PRTEE) user manual. School of Rehabilitation Science, McMaster University, Hamilton

13. Rompe JD, Overend TJ, MacDermid JC (2007) Validation of the patient-rated tennis elbow evaluation questionnaire. J Hand Ther 20(1):3-11

14. Hubbard DR, Berkoff GM (1993) Myofascial trigger points show spontaneous needle EMG activity. Spine 18(13):1803-1807
15. Langley GB, Sheppeard H (1985) The visual analogue scale: its use in pain measurement. Rheumatol Int 5(4):145-148

16. Connell D, Burke F, Coombes P, McNealy S, Freeman D, Pryde D (2001) Sonographic examination of lateral epicondylitis. Am J Roentgenol 176(3): 777-782

17. Krogh T, Fredberg U, Christensen R, Stengaard-Pedersen K, \&Ellingsen T (2013). Ultrasonographic assessment of tendon thickness, Doppler activity and bony spurs of the elbow in patients with lateral epicondylitis and healthy subjects: a reliability and agreement study. Ultraschall Med; 34(05): 468-474.

18. Palaniswamy V, Ng SK, Nagarajan Manickaraj MR, Yelland M, Rabago D, Bisset $L$ (2018) Relationship between ultrasound detected tendon abnormalities, and sensory and clinical characteristics in people with chronic lateral epicondylalgia. PLoS One 13(10):e0205171

19. Scarpone M, Rabago D, Zgierska A, Arbogast G, Snell E (2008) The efficacy of prolotherapy for lateral epicondylosis: a pilot study. Clin J Sport Med 18(3):248

20. Shin J, Seo K-M, Kim D-K, Kim B-K, Kang S-H (2002) The effect of prolotherapy on lateral epicondylitis of elbow. J Korean Acad Rehabil Med 26(6):764-768

21. Park JH, Song IS, Lee JB, Lee HY, Yoo SM, Yang SJ et al (2003) Ultrasonographic findings of healing of torn tendon in the patients with lateral epicondylitis after prolotherapy. Ultrasonography 22(3):177-183

22. Reeves KD et al (2011) Prolotherapy: regenerative injection therapy. In: Waldman SD pain Management, 2nd edn. Saunders, Philadelphia, pp 1-11

23. Hilton J (1879) On rest and pain. In: Jacobesen WHA (ed) On rest and pain, 2nd edn. William Wood \& company, New York

24. Ji R, Nackley A, Huh Y, Terrando N, Maixner W (2018) Neuroinflammation and central sensitization in chronic and widespread pain. Anesthesiology 192(2):343-366

25. Hackett GS (1959) Ligament relaxation and osteoarthritis, loose jointed versus close jointed. Rheumatism. 15(2):28-33

26. Hackett GS (1966) Uninhibited reversible antidromic vasodilation in pathophysiologic diseases: arteriosclerosis, carcinogenesis, neuritis, and osteoporosis. Angiology. 17(2):109-118

27. Caterina MJ, Schumacher MA, Tominaga M, Rosen TA, Levine JD, Julius D (1997) The capsaicin receptor: a heat-activated ion channel in the pain pathway. Nature 389(6653):816-824

28. Reeves KD (2000) Prolotherapy: basic science, clinical studies, and technique. In: Pain procedures in clinical practice, 2nd edn. Hanley and Belfus, Philadelphia, pp 172-190

29. Lyftogt J (2008) Prolotherapy for recalcitrant lumbago. Austr Musculoskel Med J 13(1):18

30. Bisset LM, Coppieters MW, Vicenzino B (2009) Sensorimotor deficits remain despite resolution of symptoms using conservative treatment in patients with tennis elbow: a randomized controlled trial. Arch Phys Med Rehabil 90(1):1-8

31. Murtezani A, Ibraimi Z, Vllasolli TO, Sllamniku S, Krasniqi S, Vokrri L (2015) Exercise and therapeutic ultrasound compared with corticosteroid injection for chronic lateral epicondylitis: a randomized controlled trial. Ortop Traumatol Rehabil 17(4):351-357

32. Langen-Pieters P, Weston P, Brantingham JW (2003) A randomized, prospective pilot study comparing chiropractic care and ultrasound for the treatment of lateral epicondylitis. EJC 50(3):211-218

33. Walz DM, Newman JS, Konin GP, Ross G (2010) Epicondylitis: pathogenesis, imaging, and treatment. Radiographics. 30(1):167-184

34. Cardinal E, Chhem RK, Beauregard CG (1998) Ultrasound-guided interventional procedures in the musculoskeletal system. Radiol Clin N Am 36(3):597-604

35. Kang SH, Seo KM, Kim DK, Shin JY, Song IS (2004) Ultrasonographic findings of chronic lateral epicondylitis with partial tear before and after prolotherapy. J Korean Acad Rehabil Med 28(1):88-93

36. Apaydin H, Bazancir Z, Altay Z (2020) Injection therapy in patients with lateral epicondylalgia: hyaluronic acid or dextrose prolotherapy? A singleblind, randomized clinical trial. J Altern Complement Med 26(12)

37. Wagle S, Glazebrook K, Moynagh M, Smith J, Sellon J,\& Skinner J et al. (2020). Role of ultrasound-guided perineural injection of the posterior antebrachial cutaneous nerve for diagnosis and potential treatment of chronic lateral elbow pain. Springer Berlin Heidelberg; 1-6.

\section{Publisher's Note}

Springer Nature remains neutral with regard to jurisdictional claims in published maps and institutional affiliations. 